\title{
Underwater observations of dolphin reactions to a distressed conspecific
}

\author{
Stan A. Kuczaj II ${ }^{1}$ - Erin E. Frick ${ }^{1} \cdot$ Brittany L. Jones ${ }^{1}$ - James S. E. Lea ${ }^{2}$. \\ Dan Beecham $^{3}$ - Fabrice Schnöller ${ }^{4}$
}

Published online: 22 April 2015

(C) Psychonomic Society, Inc. 2015

\begin{abstract}
This report describes the epimeletic (or "caregiving") behavior produced by members of a group of Atlantic bottlenose dolphins (Tursiops truncatus) and the possible role of the ailing animal's distress call in eliciting such behavior. Epimeletic behavior in cetaceans most typically involves forms of support provided to a distressed, injured, or dying animal (Caldwell \& Caldwell, 1966). Analyses of underwater video and corresponding acoustic recordings revealed a distressed dolphin (the DD) that frequently produced what are most likely distress calls, often paired with the emission of long bubble streams. The frequency of her whistle production was positively correlated with the frequency of the supporting behaviors the DD received from other dolphins. These helping behaviors included raft formations, lifts, and stimulating pushes that were predominantly directed toward the upper third of the DD's body, all of which appeared to be directed towards bringing the DD toward the surface so that she could breathe. This is the first documented underwater account of multiple wild bottlenose dolphins providing epimeletic care to a distressed conspecific, and highlights the possible role of distress calls in such scenarios.
\end{abstract}

Keywords Distress call $\cdot$ Helping behavior · Dolphins · Communication

Stan A. Kuczaj, II

s.kuczaj@usm.edu

1 Department of Psychology, University of Southern Mississippi, 118 College Drive \#5025, Hattiesburg, MS 39406, USA

2 Danah Divers Marine Research Facility, Jeddah, Saudi Arabia

3 Dan Beecham Underwater Videography, Cape Town, South Africa

4 Project Dare Win, Paris, France
Epimeletic (caregiving) behavior occurs when a healthy animal provides aid to another distressed, injured, or dying individual (Caldwell \& Caldwell, 1966). Such behavior has been found in mammalian species such as mice, Mus musculus (Williams \& Scott, 1953); dogs, Canis lupus familiaris (Scott \& Marston, 1950); wolves, Canis lupus (Scott, 1950); and several cetacean species from the Delphinidae family (for review, see Caldwell \& Caldwell, 1966; Pilleri, 1984). For example, healthy dolphins may attempt to assist and perhaps stimulate a distressed conspecific through various pushing and lifting behaviors that support the animal at the surface (de Moura, da Silva Rodrigues, \& Siciliano, 2009). Such epimeletic behaviors have been observed in both captive and wild populations in a variety of cetacean species, including rough-toothed dolphins, Steno bredanensis (de Moura et al., 2009); long-beaked common dolphins, Delphinus capensis (Park et al., 2012); La Plata dolphins, Pontoporia blainvillei (Cremer, Sliva Hardt, \& Tonello, 2006); and Atlantic bottlenose dolphins, Tursiops truncatus (Caldwell \& Caldwell, 1966; Fertl \& Schiro, 1994).

Caldwell and Caldwell (1966) discussed three different categories of behaviors exhibited by nondistressed individuals during periods of epimeletic behavior: "standing by," "excitement," and "supporting." "Standing by" occurs when animals maintain close proximity to the injured/distressed individual but provide no aid (Caldwell \& Caldwell, 1966). "Excitement" is characterized by nearby animals rapidly circling the distressed individual or exhibiting aggressive behaviors toward an apparent threat (e.g., an approaching boat or diver), but no aid is provided to the distressed individual (Caldwell \& Caldwell, 1966). The final category, "support," involves animals engaging in various pushing and lifting behaviors that assist the distressed individual to remain at the surface to breathe (Caldwell \& Caldwell, 1966) and is the only one of the three behavior types that involves direct assistance to the struggling conspecific. For example, Caldwell and Caldwell (1966) described an account of three dolphins in a captive setting that were introduced to a fourth companion who was sinking in the water column. Two of the dolphins supported 
and pushed the injured animal to the surface until it was able to swim unassisted. Staff at the facility observed the third dolphin swim around the enclosure, not offering assistance, which is consistent with the stand-by epimeletic category.

Epimeletic behavior has been classified as "nurturant" when support was directed by an adult toward a calf or juvenile, and as "succorant" when directed towards an adult (Caldwell \& Caldwell, 1966). Nurturant caregiving behavior has been documented previously in both captive and wild dolphin groups and is the most prevalent form of observed epimeletic behavior (Pilleri, 1984). The most common nurturant observations involved mothers carrying dead or stillborn calves at the surface for a prolonged period of time (Fertl \& Schiro, 1994). Succorant epimeletic behavior has been less frequently documented, but such behavior has been described in both captive and wild dolphin groups. Pilleri (1984) discussed anecdotal accounts of individual captive dolphins supporting other adult individuals at the surface. For example, Brown and Norris (1956) gave a wounded female dolphin adrenaline shots, which accidentally rendered her immobile and unable to reach the surface to breathe. They observed an adult male dolphin pushing her to the surface repeatedly until the inanimate female dolphin was revived.

Most observations of succorant epimeletic behavior in wild populations have resulted from anecdotal surface observations and have not been formally documented (Pilleri, 1984). Caldwell and Caldwell (1966) discussed surface observations of succorant epimeletic behavior in the wild, such as an incident where a charge of dynamite exploded in the water near a group of bottlenose dolphins. A single adult dolphin appeared to be stunned and rendered immobile from the explosion. Two adult dolphins swam toward the injured individual and began to lift the stunned dolphin toward the surface to breathe, until the injured dolphin was able to swim unassisted. The Caldwells also observed stand-by epimeletic behavior in this encounter, as the majority of the other dolphins in the group neither offered assistance nor left the area of the explosion. Instead, they simply remained in the potentially dangerous area until the injured dolphin could swim unassisted.

Postmortem examinations of bite and rake marks in conjunction with netting scars have also indicated possible nurturant and succorant epimeletic behavior. Cremer et al. (2006) found a stranded La Plata dolphin calf off the coast of southern Brazil. The carcass had numerous teeth marks and scratches whose size and position suggested an adult dolphin had tried to lift or carry the calf to the surface. de Moura et al. (2009) reported two fishermen's observations of an adult rough-toothed dolphin that lifted and pushed a dead juvenile male rough-toothed dolphin to the surface. Postmortem analysis found teeth marks and scratches indicative of pushing and lifting behaviors consistent with the previously outlined epimeletic definitions.
Both nurturant and succorant epimeletic events typically involve only one or two adult dolphin(s) providing support to one other individual, but sometimes appear to involve multiple helping animals (Cockcroft \& Sauer, 1990; de Moura et al., 2009; Park et al., 2012; Ritter, 2007; Siebenaler \& Caldwell, 1956; Warren-Smith \& Dunn, 2006). Park et al. (2012) observed several wild long-beaked common dolphins, Delphinus capensis, in the East Sea, engaging in caregiving supportive behaviors directed toward a dying conspecific at the surface. These behaviors included pushes toward the surface, pushes to the head and upper body of the dying animal, and "raft" formations (i.e., several animals using their body to lift the upper and lower body of the distressed individual simultaneously) in order to keep the dying individual at the surface. Their observations were the first documented account of multiple adult animals simultaneously providing succorant epimeletic support toward the same individual. However, the account by Park et al. (2012) did not include an examination of the acoustic signals being emitted by any of the animals during the encounter.

Distress calls are emitted by animals in a variety of contexts, such as an attack from a predator or severe injury or illness (Vannoni, Torriani, \& McElligott, 2005). Multiple species have been found to use distress calls that elicit help from conspecifics (e.g., bats, birds, and deer; Russ, Jones, Mackie, \& Racey, 2004; Stefanski \& Falls, 1972; Vannoni et al., 2005). Such calls generally consist of repeated bursts of sound that cover a wide frequency range (Marler, 1955; Marten \& Marler, 1977). Richardson, Jacobson, Muncy, and Perkins (1983) found that deer distress calls were prolonged and continuously repeated vocalizations that often lasted until the deer was no longer capable of calling. Distress calls in cetaceans were first described by Lilly (1963) as a repetitive whistle emitted by an animal in order to elicit aid from another animal. Such whistling could last for hours if sufficient help was not obtained. Both Esch, Sayigh, Blum, and Wells (2009) and Watwood, Owens, Tyack, and Wells (2005) found a significant increase in whistle rate from bottlenose dolphins during a temporary capture when compared to those same animals' whistle rate during free-range swimming. Esch et al. (2009) also found an increase in the number of whistle loops during capture-release sessions. Similarly, May-Collado (2010) hypothesized that Guyana dolphins altered their whistle parameters (i.e., lowered frequency, slightly longer duration) in order to express distress to conspecifics during harassment from bottlenose dolphins. These findings suggest that varying whistle rate along with other features may allow additional information, such as distress, to be communicated through whistles.

Caldwell and Caldwell (1965) suggested that dolphins produce individually distinct stereotyped whistles, (i.e., signature whistles) which serve as contact calls. They found that animals in distress may produce their signature whistle more 
intensely, more frequently, faster, louder, and with a more variable number of loops compared to "normal," or baseline, recordings of their stereotyped whistle. They also reported that the typical whistle of an animal seems to quaver and contain more abrupt discontinuities when the animal is in stressful situations. Buckstaff (2004) reported an increase in signature whistle use during watercraft approach in Sarasota Bay, suggesting this may be a stressful context in the wild. Similarly, Ridgway (1983) noted that an ill female bottlenose dolphin produced one stereotyped whistle contour repeatedly. These findings suggest that the rates and intensity with which whistle contours are emitted may signal distress to conspecifics (Janik, 2009).

Contact calls in dolphins may serve to facilitate reunions and maintain group cohesion (Caldwell, Caldwell, \& Tyack, 1990), whereas distress calls function to elicit a caregiving response and more urgent approach by others. It is important to note that the same contour shape seems to be used by a given individual in both contact and distress contexts, but the rate, intensity, duration, and repetitions of that signature contour varies depending on context. Contact calls and distress calls also appear to differ in terms of the sounds emitted by the animals surrounding the vocalizing individual. Lilly (1965) found that when a distress whistle occurred, the surrounding animals significantly reduced their vocalization rates. In contrast, contact calls result in various forms of vocal reactions from surrounding animals. For example, recordings from isolated but nondistressed individuals (Caldwell et al., 1990) resulted in an increased contact vocalization rate until another dolphin was added into the enclosure. McBride and Hebb (1948) reported that a mother repeated a contact call while separated from her calf until the calf returned, at which point the mother ceased to whistle. Contact calls seem to have a number of different functions, including maintaining group cohesion, announcing individual identities, and facilitating reunions, whereas distress calls seem to have a specific purpose. Distressed individuals vocalize repeatedly even after another animal approaches, or attempts to help, until sufficient aid has been received (Lilly, 1965). For example, Herzing (1996) reported that a calf repeatedly emitted a distress vocalization until another animal was able to calm him down by repeated pectoral petting.

In summary, signature whistles seem to be used as both distress calls and contact calls, but their use in these contexts differ in three fundamental ways:

1. A distress call elicits help from a healthy animal, whereas a contact call facilitates cohesion and may elicit a vocal reaction from or a reunion with another animal.

2. A distress call is repeated consistently until sufficient aid is received, whereas a contact call is more likely to stop once the reunion is complete.

3. Other animals typically decrease their vocalization rates following a distress call, whereas contact calls that are facilitating group cohesion result in an increase in vocal responses.

Previous anecdotes and published documentation of epimeletic behavior have been limited to surface observations and rarely provided considerations of the acoustic behavior that accompanied overt helping behavior. The present account describes a rare underwater perspective of possible epimeletic behavior, including the acoustical behaviors that were produced by both the distressed dolphin and the dolphins in the surrounding vicinity. The presence of previously documented supporting behaviors, augmented by what appears to be a constantly emitted distress call, support the conclusion that this event involved multiple dolphins providing succorant epimeletic support to a distressed dolphin, hereafter referred to as the DD.

\section{Method}

\section{Survey site}

In September 2012, James Lea and videographer Dan Beecham were surveying silky shark populations in the Red Sea, off the coast of Jeddah, Saudi Arabia, as part of ongoing research on the movement of the sharks in this area (Clarke, Lea, \& Ormond, 2011, 2013). James and Dan encountered a group of wild bottlenose dolphins surrounding a slim adult dolphin that appeared to be in distress, in waters approximately $300 \mathrm{~m}$ deep. Dan videotaped the opportunistic encounter and at no time attempted to interfere with the dolphins. This research complied with applicable regulations.

\section{Data collection}

Simultaneous underwater video and audio were recorded opportunistically, totaling 18 minutes and 29 seconds of recordings. An estimated range of 2 to 25 dolphins were present onscreen at a given moment throughout the video, and sex was determined for any animal for which the genital slit could be clearly observed. The DD first appeared onscreen at $5 \mathrm{mi}-$ nutes and 28 seconds, and appeared to be in distress. The video data were collected using a focal follow sampling method, with the DD as the focal animal for recording (Altmann, 1974). The DD was no longer observed on film after 15 minutes and 33 seconds. We report on all dolphin acoustic and nonacoustic behaviors that occurred during the entire encounter.

\section{Data analysis}

Video data were coded and analyzed using an all occurrence sampling method for all nonacoustic dolphin behaviors 
(Altmann, 1974). Behaviors for the DD, aid providers, and other nearby conspecifics were included in the data analysis. Definitions for the nonacoustic behaviors are listed in Table 1. A behavior chronology of each video segment of the encounter was compiled (see Fig. 1). Interobserver reliability was obtained for identification of the DD, correct frequency and identification of nonacoustic behaviors, body positions, and whistle contours. Reliability was assessed using a Pearson's coefficient $(r=.821)$ in order to facilitate accurate interpretation of the data (Sharpe \& Koperwas, 2003).

Acoustic behaviors were extracted from the video footage (sampling rate of $32 \mathrm{kHz}[1]$ ) using Raven Pro $1.4^{\circ}$, an acoustical analysis software from the Cornell Lab of Ornithology. The acoustic data were then matched to the behavioral interactions using a timeline. The "DD whistle" contour depicted in Fig. 9 was of particular interest, as the interwhistle interval calculated during whistle bouts identified this contour as a signature whistle of one of the wild dolphins on the recording (see Janik, King, Sayigh, \& Wells, 2013, concerning the identification of signature whistles when localization is not possible). Using bubble-stream emission as an additional aid for identifying the whistler (Wood, 1954), along with behavioral cues (e.g., the DD whistle contour breaking off as the DD took a breath at the surface) and the presence of the DD in frame, it appeared that this one specific whistle type was most often being repeatedly produced by the DD (see Fig. 2). The duration of this whistle was highly variable, ranging from about 0.6 to 3.5 seconds. Although bubble-stream emissions may not be fully representative of the full acoustic repertoire of a given dolphin (Fripp, 2005), they are often used as an additional cue to aid researchers in identifying the vocalizer when other localization methods are unavailable. Here, whistle rates were determined by visual inspection of spectrograms. Individual whistle contours were counted as one whisthe if they were continuous (i.e., no breaks in the fundamental frequency band exceeding . $25 \mathrm{~s}$ ), narrowband frequency modulated signals (following Sayigh, Esch, Wells, \& Janik, 2007). Unfortunately, the limited sampling rate of the video recorder made it impossible to determine the full spectral analysis of the whistle contours. Consequently, we elected to focus on the presence or absence of the "DD" whistle contour.

Table 1 List of all behaviors, their definitions, and their codes used during the video coding analysis

\begin{tabular}{|c|c|c|}
\hline Code & Behavior & Definition \\
\hline APP & Approach & One animal quickly draws closer to another and an interaction occurs \\
\hline BRH & Breath** & Breaks surface to inhale and exhale air \\
\hline BSW & Blast swim & Swift burst of speed toward the surface preceded by slow swimming/nonmovement \\
\hline BBU & Bubble burst & Dolphin emits cloud of bubbles similar to the release of air from scuba equipment \\
\hline BBS & Bubble stream & Dolphin emits a trail of tiny bubbles \\
\hline CSW & Contact swim & Dolphins swimming close while maintaining contact of 1 body part to another \\
\hline DSA & Distress surface with assistance & Distressed dolphin breaking surface due to assistance of helper dolphin(s) \\
\hline DIA & Dive to assist & Usually originating near surface, 1 dolphin diving and orienting toward the distressed dolphin \\
\hline GRP & Group Swim & $\begin{array}{l}\text { Three or more dolphins are swimming in same direction within a (dolphin) body length of } \\
\text { each other. } \sim 1.5 \mathrm{~m}\end{array}$ \\
\hline OTC & Orient to camera & Dolphin turns head to camera \\
\hline OTD & Orient to dolphin & Dolphin turns head toward another dolphin \\
\hline $\mathrm{OTH}$ & Other & Any behavior other than those defined by the ethogram \\
\hline PRS & Pair swim & Dolphin is swimming in same direction as another within a dolphin body length \\
\hline PUU & Push & One dolphin drives another in a given direction \\
\hline PUD & * Toward Surface & \\
\hline PDD & *Down & \\
\hline PR & *Recipient & \\
\hline RAM & Ram & One dolphin hits another dolphin very hard/forcibly, propelling it in a given direction \\
\hline SEX & Sexual contact & $\begin{array}{l}\text { Dolphin is interacting with another sexually as evidenced by genital-genital contact, rostrum/fin/ } \\
\text { other bodily contact with another's genitals, or an erection and copulation attempt }\end{array}$ \\
\hline SKD & Sink down & Stationary, sinking deeper into water \\
\hline SUS & Suspended swim & Dolphin underwater, immobile. Suspended in water, not sinking or rising \\
\hline TCT & Tactile & $\begin{array}{l}\text { One dolphin makes physical contact with another. When coding-TCT/body part that contacts } \\
\text { the other dolphin }\end{array}$ \\
\hline
\end{tabular}

** denotes a behavior that was only coded for the DD. Behaviors are adapted from Caldwell and Caldwell (1966), Dudzinski (1996), Pilleri (1984), and Park et al. (2012) 


\begin{tabular}{|c|c|c|}
\hline Time & Segment & Description \\
\hline 05:28-09:05 & 1 & $\begin{array}{l}4 \text { dolphins approach the DD (vertical position) and begin to circle, push, } \\
\text { and lift the DD toward surface. } \sim 6 \text { other dolphins in a group visible, } \\
\text { milling near (all adults, no calves present). Repeated whistle heard from } \\
\text { DD, little to none observed from other dolphins. Long continuous bubble } \\
\text { streams observed by the DD, during a long sinking period that starts at } \\
0: 06: 26 \text { minutes, with } \sim 4 \text { dolphins diving to assist and push the DD. DD } \\
\text { is stimulated and swims to surface at } 0: 07: 32 \text {, then regresses to a sinking } \\
\text { state. The DD receives continued pushing and support at surface by } 3 \\
\text { dolphins, with } \sim 4 \text { other dolphins milling near. }\end{array}$ \\
\hline 09:05-10:50 & 2 & $\begin{array}{l}\text { The DD sinking in vertical position, approached and aided by } 2 \\
\text { dolphins, joined by a third (all adults). The DD is stimulated and swims } \\
\text { to surface, emits long bubble streams interrupted by lifts to breathe at } \\
\text { surface. } \sim 3 \text { other dolphins milling, joined by } \sim 8 \text { other dolphins. } \sim 11 \\
\text { non-supportive, } 4 \text { supportive and the DD observed slowly swimming in } \\
\text { a group, no calves present. }\end{array}$ \\
\hline 10:50-11:14 & 3 & $\begin{array}{l}3 \text { dolphins push and lift the DD while she is bubble streaming, and one } \\
\text { helper releases a bubble burst. } \sim 6 \text { adult dolphins in a group milling. }\end{array}$ \\
\hline 11:14-11:55 & 4 & $\begin{array}{l}\text { The DD in vertical position, immobile, with } 3 \text { supportive dolphins. One } \\
\text { attempts to copulate before all } 3 \text { engage in pushes and lifts. } \sim 6 \text { dolphins } \\
\text { milling behind the DD. The DD is stimulated, and swims rapidly toward } \\
\text { surface with one helper, } \sim 10 \text { dolphins slowly follow. }\end{array}$ \\
\hline $11: 55-12: 22$ & 5 & $\sim 12$ dolphins (all adults) slowly group swim \\
\hline 12:22-13:10 & 6 & $\begin{array}{l}\sim 7 \text { dolphins in small groups. The DD and } 1 \text { helper appear at } 0: 12: 30 \text {. } \\
\sim 15 \text { total dolphins on screen, the DD and aid-providing companion join } \\
\text { the group, all slow group swim at surface briefly, The DD regresses to } \\
\text { sinking state, and several dolphins swimming underneath the DD lift her } \\
\text { to the surface. }\end{array}$ \\
\hline $13: 10-15: 33$ & 7 & $\begin{array}{l}\text { Group of dolphins including the DD present, circling and milling, } \sim 4-5 \\
\text { providing support to the DD. They lifted the DD at the surface, and rolls } \\
\text { across the supporting dolphins' backs, raft formation. } 0: 13: 46 \sim 12 \\
\text { dolphins group swim including } \sim 4 \text { dolphins pushing immobile DD } \\
\text { forward with group (all adults). The DD begins sinking deep into water } \\
\text { column in vertical position, } \sim 9 \text { dolphins mill near surface and } 3 \text { dive to } \\
\text { assist and push the DD. The DD sinks deeper into the water column. }\end{array}$ \\
\hline
\end{tabular}

Fig. 1 Behavior chronology. Video data with the DD present on-screen were divided into 7 segments based upon when video feed stopped and restarted. A general description of what occurred in each of these segments was summarized

"Other whistle contours" were defined as any other narrowband, frequency modulated vocalization not categorized as a "DD whistle contour." All "other whistle contours" were

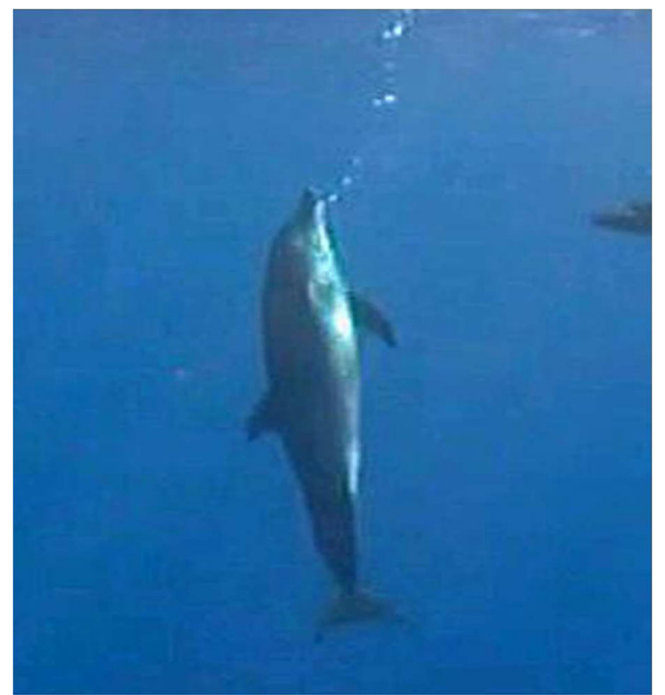

Fig. 2 The DD sinking in the water column while in the vertical position and emitting a bubble stream grouped into one category, as the whistler's identity in these cases could not be reliably determined.

\section{Results}

One of us (D. B.) began filming a group of bottlenose dolphins, and focused the video on the DD once she appeared (i.e., 0:05:28 after filming began). The DD was a slim, female Atlantic bottlenose dolphin that appeared to be in distress. She had no obvious physical injuries, although it is possible that there was some damage to her left eye. The DD exhibited an immobile state in the water column for the majority of the encounter. This state was characterized by lack of active movement of her flukes, head, body, and/or pectoral fins (see Fig. 2).

The position of the DD was predominantly vertical in the immobile state, flukes down, with rostrum toward the surface, and only changed to horizontal (i.e., ventral up or dorsal up) as she received pushes toward the surface from several helping dolphins. During this encounter the DD exhibited no active movement to maintain her vertical position. However, her vertical position did change when other dolphins intervened. 
The observed vertical position occurred in a variety of contexts (when alone, receiving support, sinking, in a group) and was typically accompanied by the constant emission of bubble streams.

Approximately 20 adult dolphins were viewed onscreen during the encounter, with 4 to 5 individuals engaging in supportive lifting and pushing behavior at a time. Both males and females provided aid to the DD. Unfortunately, the lack of reliable identifiable marks on most of the dolphins made it impossible to determine whether the same individuals engaged in supportive behavior toward the DD throughout the encounter. No biting or raking behaviors were observed in this encounter. Of the 58 observed supportive pushing behaviors (see Fig. 3), approximately $70 \%$ of all pushes and lifts received by the DD (see Fig. 4) were directed toward the upper third of her body, $\chi^{2}(8, N=58)=45.341, p<.05$, indicating a preference for directing supportive behaviors toward this body area. Dolphins that provided support were most likely to use the area around their head to stimulate and lift the DD toward the surface, $\chi^{2}(8, N=58)=141.661, p<.05$ (see Fig. 5). Only one push was received by the DD in the genital region. $.02 \%$ of all pushes received). Lifting behaviors used by the helping dolphins included: (1) using their rostrum or head to lift the DD to the surface (see Fig. 6), and (2) multiple helping dolphins swimming underneath and simultaneously supporting both the upper and lower body of the DD as she took a breath (see Fig. 7).

There were several instances where the DD was immobile and slowly sank for brief periods of time. However, there were two long sinking periods ( $\geq 60$ seconds) where the DD remained in a vertical position and sank to a depth of approximately $30 \mathrm{~m}$ or greater. Continuous bubble streams and whistles were emitted as she sank deeper into the water column. Typically, 4 to 5 helping individuals dove to assist the DD by

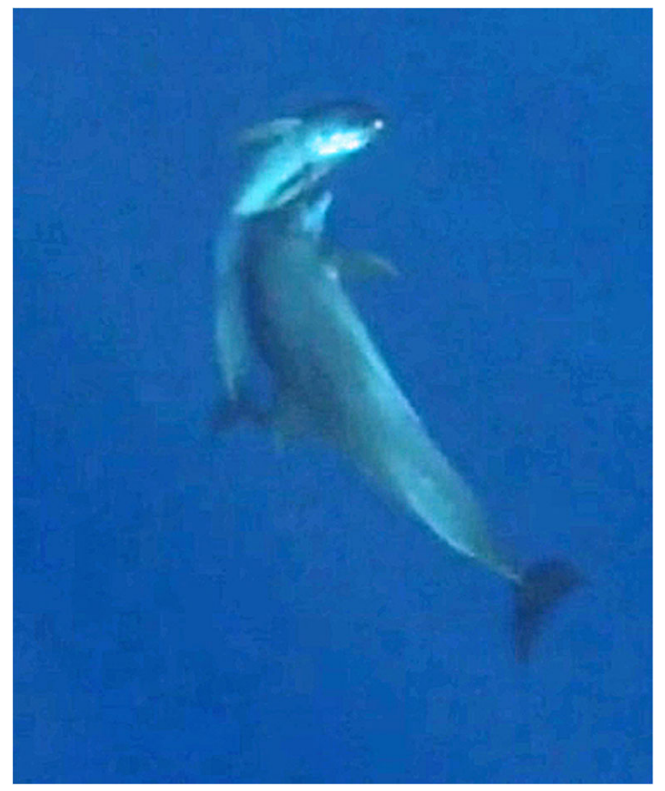

Fig. 3 Example of a supportive push behavior engaging in upward pushing behavior. The time periods during which dolphins assisted DD were defined as "bouts" of caregiving behavior. A bout of caregiving behavior began when an aid-providing dolphin pushed/lifted the DD and ended when no aid was provided for 10 consecutive seconds. Ten bouts of aid-providing behavior were recorded in this encounter, with the shortest lasting 10 seconds and the longest lasting 2 minutes and 20 seconds. The number of aid-providing dolphins ranged from 2 to 5 . At the end of each bout, the DD appeared to be stimulated to move by the helper dolphins, at which point she quickly swam to the surface to breathe, but a few seconds later returned to either an immobile or a sinking state.

Throughout the encounter there was a frequently emitted repeated whistle contour of varying length and intensity, most often observed while the DD was constantly emitting bubble streams. These whistles lasted for varying lengths of time and were typically interrupted by the DD taking a breath. This whistle contour was identified as a signature whistle of a dolphin by calculating interwhistle interval over whistle bouts (see Janik et al., 2013). There were many whistle bouts, characterized as a time segment defined by emissions of whistles of the same contour repeated within 10 seconds of one another. Four or more whistles of the same contour occurred in each bout, and at least $75 \%$ of those whistles occurred between 1 and 10 seconds of one another (e.g., 6:00-6:30). These criteria accord with those suggested by Janik et al. (2013) to assess signature whistles in wild bottlenose dolphins. These whistles also typically coincided with the bubble-stream emissions and exhibited the aforementioned characteristics distinguishing contact calls from distress calls (see Figs. 8, 9 and 10).

The putative epimeletic behavior of the other dolphins appeared to be influenced by this repeated whistle contour. (1) A positive correlation was found between supporting behaviors (e.g., pushes, and lifts) and the repeated "DD whistle," $r=$ $.652 ; p<.05$, suggesting that this whistle possibly served to elicit helping behaviors from the other animals (see Fig. 8). (2) The DD's distress whistle was consistently repeated before, during, and after the DD received lifting and supportive pushing behaviors. An example sequence of a series of pushing behaviors received by the DD and how they corresponded to her whistles is shown in Fig. 9. (3) There was a significantly negative relationship between the frequency of the "DD whistle" and the frequency of other whistle contours ( $r=$ $-.521, p<.05)$. The whistle rate per minute of the "DD whistle" compared to the "other contours" is shown in Fig. 10. As the rate of the DD whistles increased, the other animals significantly decreased their whistling rate.

The DD whistle was produced 282 times over the 18 minute and 29 second recording (average 15.26 times per minute) while all other whistles combined (group size up to 20 animals) averaged 24.08 times per minute. The next most commonly repeated whistle contour other than the DD whistle was repeated a total of 31 times (average 1.68 whistles per minute). 


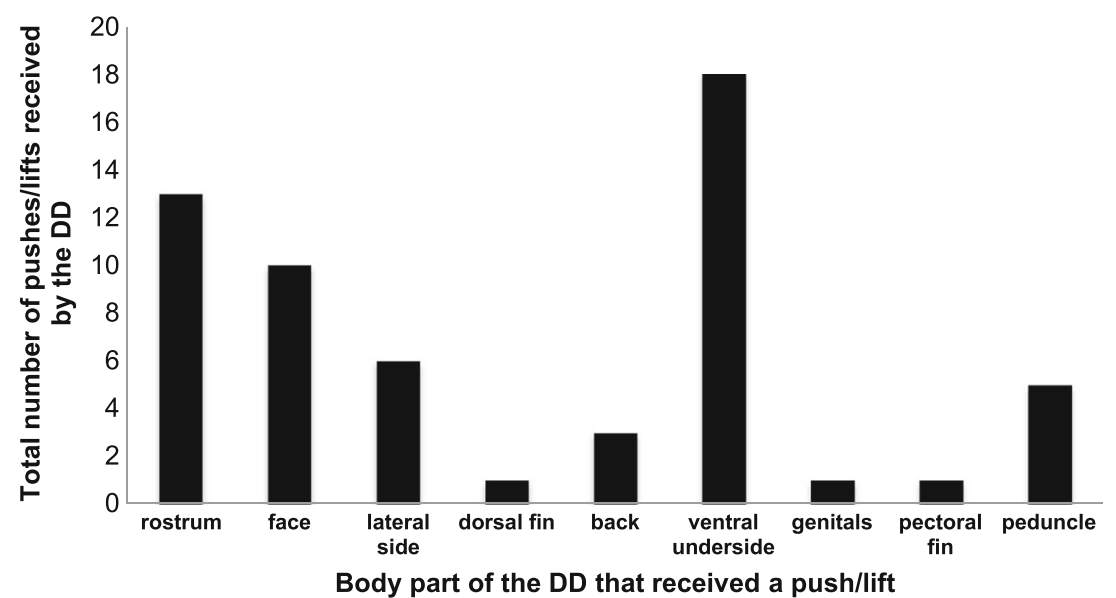

Fig. 4 Number of pushes per body part of the DD where pushes were received. Pushes were predominantly directed toward the upper third of the DD's body and appeared to function to push her upper body toward the surface, possibly to facilitate breathing

A comparison of a spectrogram from a time period prior to the first time the DD was first on camera, with a spectrogram of whistles that occurred when the DD was sinking in the vertical column is shown in Fig. 11a and b.

\section{Discussion}

The DD maintained a vertical position during the majority of her immobile, sinking states. Vertical posturing has been observed in a variety of contexts, including spontaneous pointing behavior in bottlenose dolphins (Xitco, Gory, \& Kuczaj, 2001), orienting toward dead conspecifics (Dudzinski et al., 2003), and mating avoidance in spinner dolphins (Silva, Silva, \& Sazima, 2005). Vertical positioning with limited to no active movement by a dolphin has also been seen in play behavior in bottlenose dolphins (Kuczaj \& Makecha, 2008). The vertical posturing of the DD in this study did not appear to be intended to direct the attention of other dolphins to other animals or objects, to avoid amorous males, or some sort of play signal. Her vertical posturing may have been a visual signal of distress that accompanied her hypothesized whistle signals, or may simply have reflected her inability to readily move through the water.

Mating behaviors were rarely observed throughout the entire encounter by any of the on-screen dolphins. Two sexual behaviors were directed toward the DD, each involving a male dolphin displaying a penile erection and attempting to mount the DD. Whether the same male engaged in both sexual behaviors is unknown. The relative lack of sexual behavior observed during this encounter suggests that the pushes directed at the DD by the aid providers were not sexually motivated. The supportive behaviors the DD received appear to be independent of her body position, although as noted above, it is possible that her continued use of this vertical posture somehow signaled distress to the others in her group. The minimal movement of the DD in the vertical position might also be a method of energy conservation, as it is consistent with reports that vertical posturing typically requires minimal active effort (Dudzinski et al., 2003).

The supportive behaviors produced by helper dolphins were primarily pushes and lifts that appeared to be aimed at bringing the DD toward the surface to facilitate breathing, and to stimulate the DD while she was in an immobile sinking

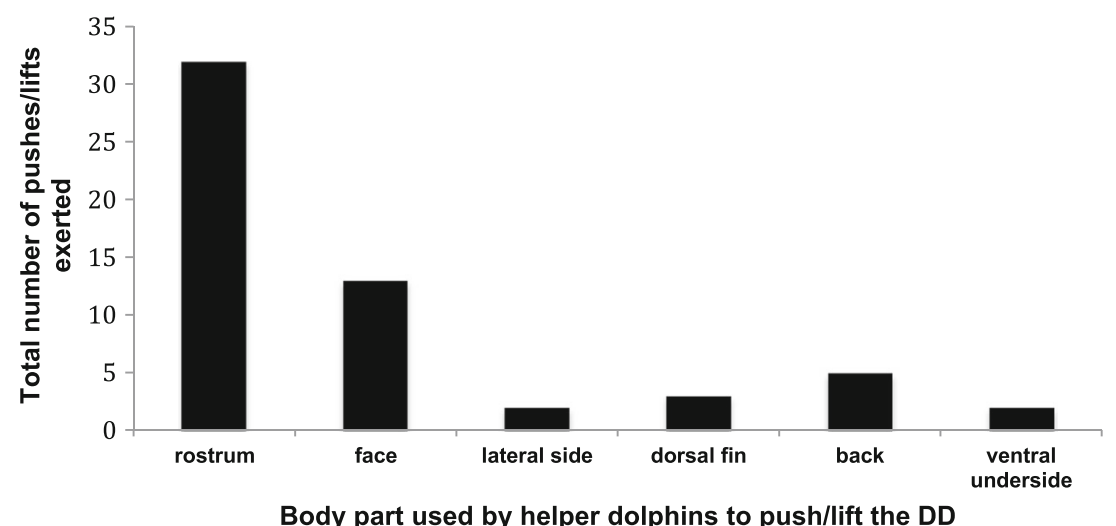

Fig. 5 Number of pushes by each body part used by helper dolphins to push/lift the DD. Helper dolphins predominantly used their head/rostrum to push and lift the DD 


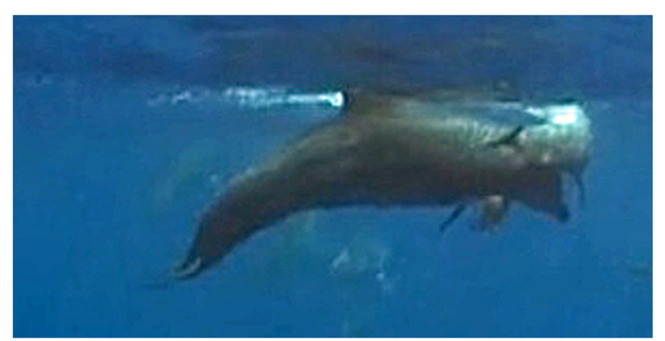

Fig. 6 The DD receives a lift toward the surface. One helping dolphin uses its melon/head to lift the peduncle of the DD while the DD is in the ventral-up body position

state. Most of the pushes and lifts were directed toward the head and rostrum of the DD. Being repeatedly pushed by other dolphins seemed to result in the DD becoming active for short periods of time, for example, swimming alongside one of the helping dolphins toward the surface to breathe for a few seconds before regressing back to the immobile state for several minutes. These bouts of receiving stimulating pushes followed by a brief, few seconds of activated movement was observed several times throughout the encounter, until the final sinking period at 15 minutes 33 seconds into the recording, where the DD sinks deep in the water column until she is no longer visible, and is not seen again in any subsequent video or surface observations. These observed helping behaviors are consistent with the "support" category of epimeletic behavior identified by Caldwell and Caldwell (1966) in that the pushing behaviors of the helping dolphins appeared to have stimulated the DD.

Some reports of epimeletic behavior involve one individual providing aid to another (Caldwell \& Caldwell, 1966; Pilleri, 1984; Fertl \& Schiro, 1994), but others appear to involve cooperative efforts to assist injured or ill companions (Cockcroft \& Sauer, 1990; de Moura et al., 2009; Siebenaler \& Caldwell, 1956; Park et al., 2012; Ritter, 2007; WarrenSmith \& Dunn, 2006). Dolphins are known to cooperate in foraging, mating, play, and problem-solving contexts (Connor, Smolker, \& Richards, 1992; Kuczaj \& Eskelinen, 2014; Kuczaj, Winship, \& Eskelinen, 2015), and the results

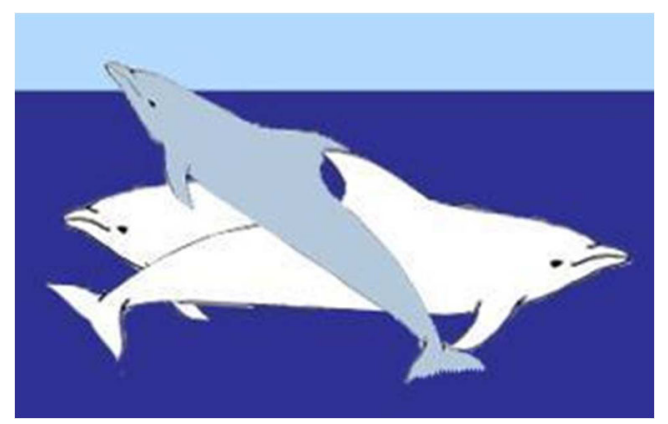

Fig. 7 An illustration of the DD being lifted by (2) helping dolphins. Two helping dolphins swim underneath the DD and appear to use their backs to lift the DD to the surface to allow her to breathe

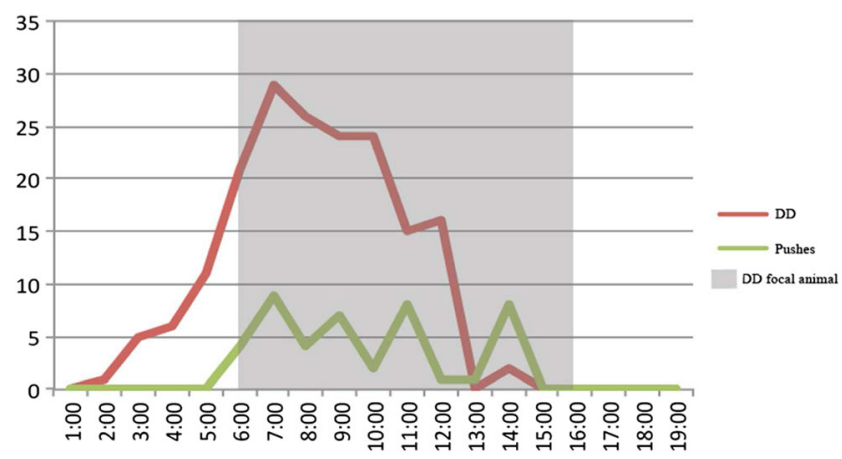

Fig. 8 Distress calls vs. pushes received. Relationship of the frequency of the DD whistle to "bouts" of aid-providing behavior

reported here are consistent with previous reports of dolphins cooperating to assist another animal. Here, 4 to 5 individuals sometimes approached the DD to lift and push her toward the surface together during an aid-providing bout. But it is impossible for us to determine the extent to which these efforts were truly cooperative rather than independent behaviors that appeared cooperative.

Cooperation may be defined as any behavior that provides a benefit to an individual other than the cooperator (Stevens, Cushman, \& Hauser, 2005). Kin selection is one of the driving forces behind cooperative behavior (Hamilton, 1964), the basic idea being that helping one's kin increases the chances of at least some of one's genes surviving and being passed along to the next generation (Emlen, 1997; Griffin \& West, 2003). Reciprocity may play a role in cooperative behavior among nonkin, assisting another being an investment that the assistance will be reciprocated in the future (Clutton-Brock, 2009; Connor \& Norris, 1982; Nowak, 2006). Given that the genetic and social relationships between the aid-providing dolphins and the DD could not be determined, we cannot ascertain the mechanisms driving the observed apparent cooperative helping behavior.

Throughout the encounter anywhere from 2 to 25 bottlenose dolphins were visible during the aid-providing bouts. Some individuals swam slowly in close proximity to the DD but did not provide any direct assistance. Although the DD occasionally swam with the entire group of dolphins after she had been stimulated by helping dolphins, once she reverted to an immobile or sinking state, usually 4 or 5 dolphins would dive to assist her while the remainder of the group slowly swam in the nearby area. Such behaviors by non-aid providing dolphins are similar to other observations of "stand by" behavior, where the group maintains close proximity but does not offer assistance (Caldwell \& Caldwell, 1966). It proved impossible to reliably identify each individual dolphin in this encounter, and so it is unknown if there were individuals that never provided aid at any point to the $\mathrm{DD}$, provided aid only sometimes, or if the same individuals always provided the assistance to the DD. 


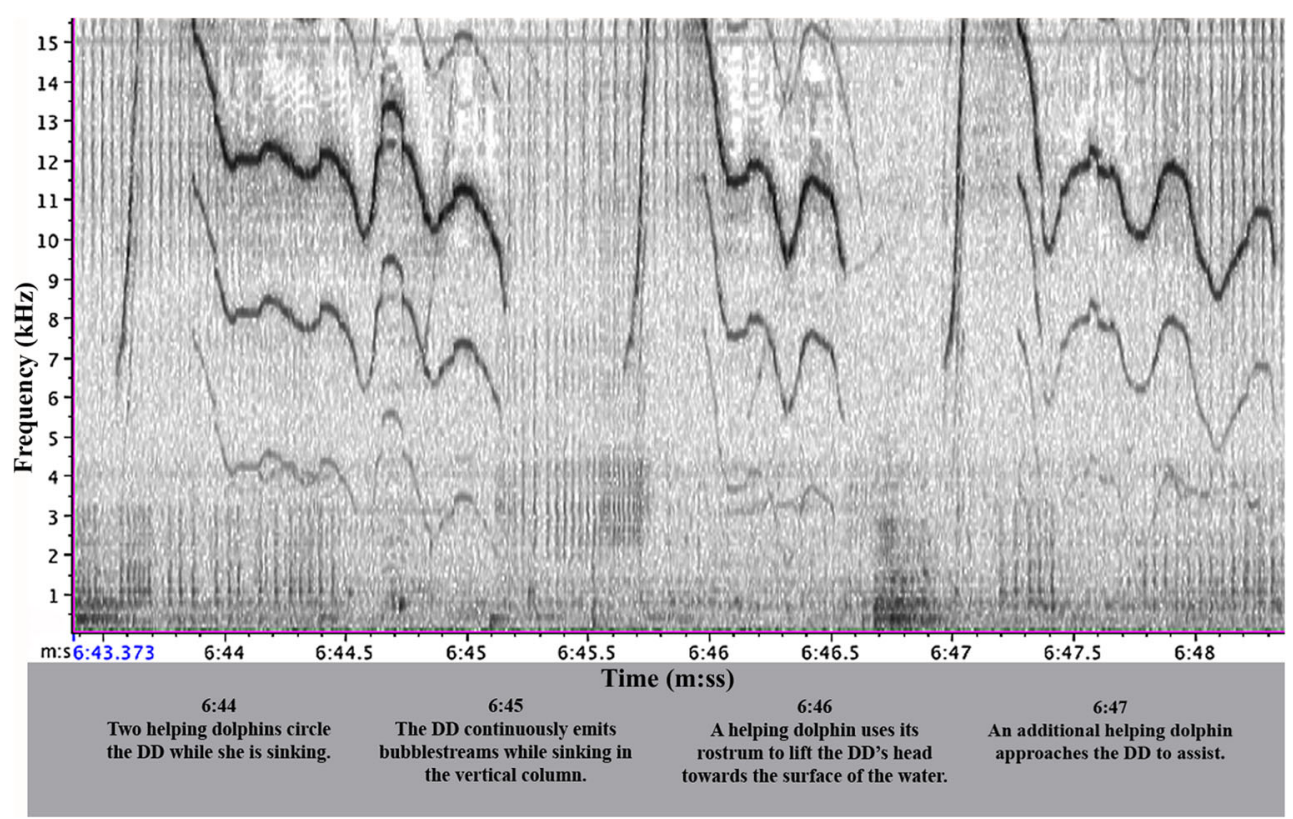

Fig. 9 The DD whistles and corresponding behavioral timeline. Example of a spectrogram taken from a behavioral period where two helping dolphins were pushing the DD to the surface. The DD whistle was repeatedly produced during this time $(\sim 282 \times$ in 18 minutes and 29 seconds, $\sim 14.7 \times$ a minute $)$

The distinctive long sinking periods exhibited by the DD when in the vertical position were normally accompanied by continuous bubble-stream emissions. Neither the DD nor any other dolphin attempted to manipulate or interact with the DD's bubble streams, consistent with the hypothesis that the observed bubble streams were not produced in a playful context. The bubble streams emitted by the DD were likely associated with the reiterated whistle emissions and may have further served as a communicative visual signal (Fripp, 2005), but they could also have been a symptom of what ailed her. Herzing (1996) found that spotted dolphins emitted a distress or excitement vocalization categorized as the repeated emission of a variation of their signature whistle. This vocalization was accompanied by erratic swimming behavior and the emission of continuous bubble streams. Within 30 seconds of this vocalization and behavior pattern, another conspecific

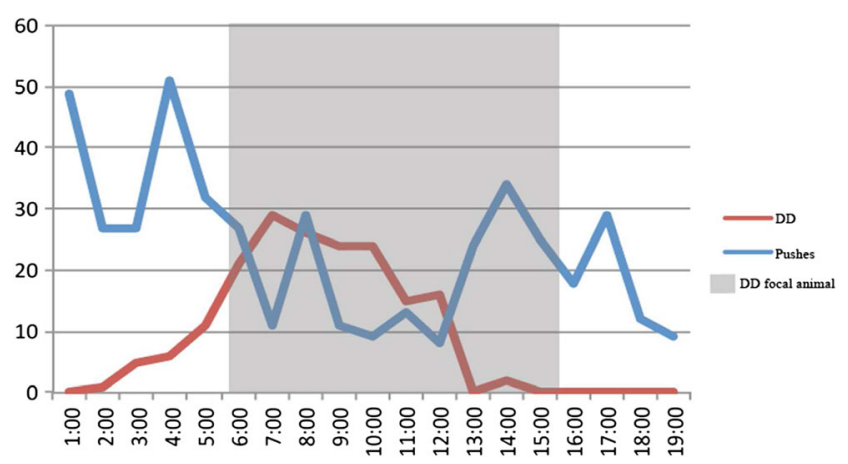

Fig. 10 Number of vocalizations per minute. Comparison of the DD distress whistle rate over time compared to all other whistles would attend to the distressed individual. This interactive sequence was most likely to involve calves under three years of age (Herzing, 1996), and so appears to possibly be a form of nurturant epimeletic support. The constant emission of bubble streams by the DD in this study could similarly be an indicator of distress, but in the succorant context. The specific communicative purpose(s) of bubble-stream emission is currently unknown (van Der Woude, 2009) and the potential role of bubble streams in distressed or injured individuals in relation to epimeletic behavior warrants further study.

The consistently repeated, intense whistle fits the criteria suggested for distress calls (Caldwell et al., 1990; Herzing, 1996; Lilly, 1965; McBride \& Hebb, 1948). Although it seems likely that this whistle contour was the DD's signature whistle, bottlenose dolphins sometimes produce the signature whistle contours of conspecifics (King, Harley, \& Janik, 2014; King, Sayigh, Wells, Fellner, \& Janik, 2013). Therefore, we cannot be certain that all of the "DD" whistle contours were emitted by the DD herself, or if some contour emissions were other animals matching her whistle type. In addition, some of the "other whistle contour" emissions may have been emitted by the DD. However, the DD whistle contour was repeated at a very high rate with high intensity, which fits the aforementioned characteristics of distress calls (Caldwell \& Caldwell, 1965; Lilly, 1963). Esch et al. (2009) found that temporarily captured female dolphins whistled more frequently than did temporarily captured male dolphins. Perhaps the DD whistled as frequently as she did because she was a female in distress, but relevant comparisons with distressed males are lacking, thus the relative roles of gender and distress on whistle rate remains unknown. 

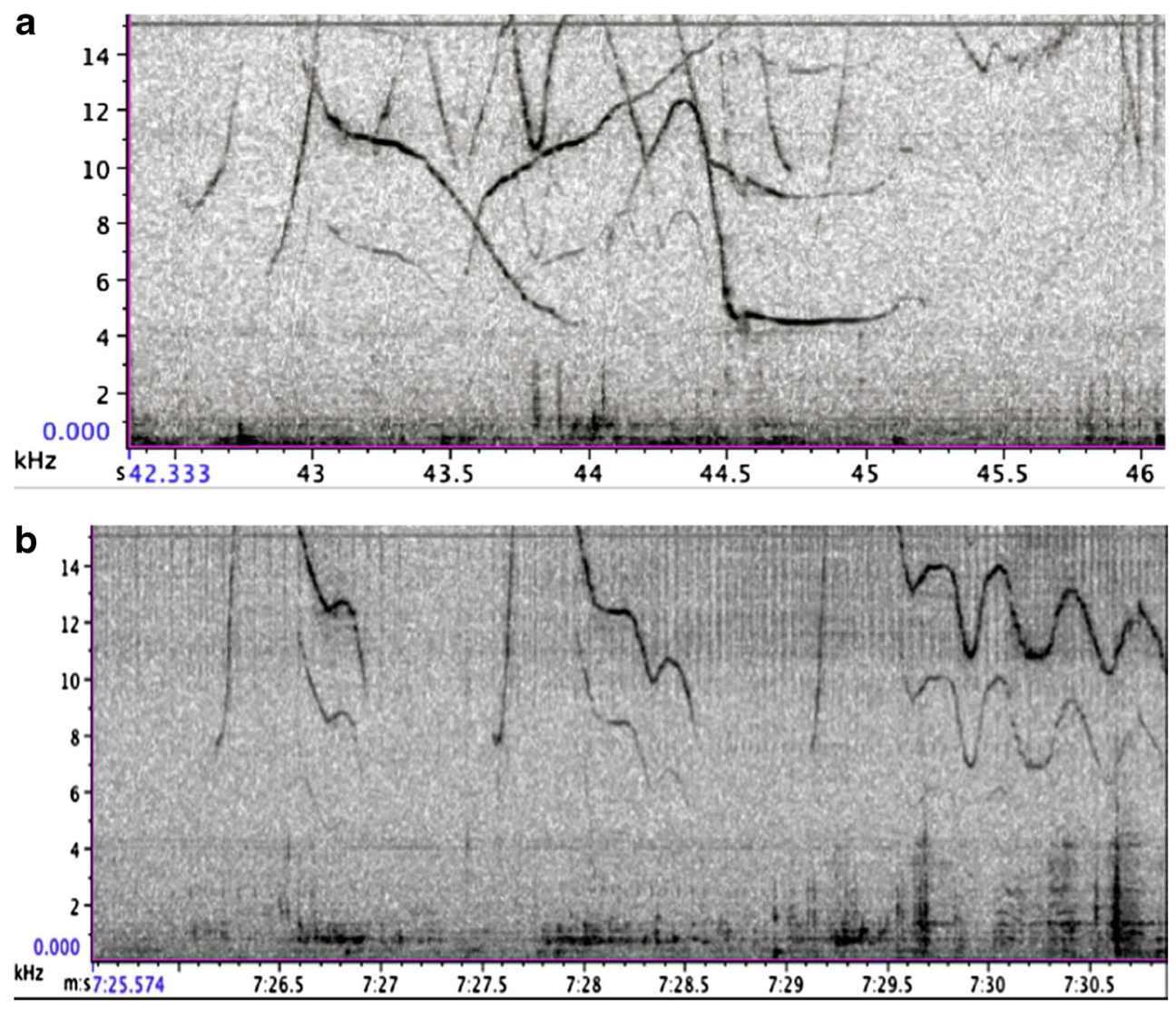

Fig. 11 a. Example of a spectrogram before the first sighting of the DD, with many dolphins whistling at once. b. Example of spectrogram when silence from other animals. The variable number of loops across whistles is consistent with other reports of distress calls in dolphins (Caldwell \& Caldwell, 1965)

The hypothesized epimeletic behavior of the other dolphins is consistent with the notion that these distress calls signaled the need for assistance. The DD whistle contour emissions appeared to elicit tactile, supportive reactions from a number of surrounding animals. The whistles were produced before, during, and after these supportive behaviors, consistent with the notion that the distress vocalizations would continue until sufficient aid was received by the DD. The significant decrease in the vocalizations of the other whistle contours suggests that distress signals may suppress vocalizations not affiliated with such distress. It is unclear if this suppression occurred because the distress calls produced emotional responses in the receivers (Kuczaj \& Horback, 2013), or if animals might become silent in order to better perceive the distressed individual's calls.

The duration of the distress whistle was highly variable, whereas the contour remained relatively consistent. Amundin (1991) also found that the distress calls in harbour porpoises had long but varying durations. Esch et al. (2009) reported an increase in the number of loops in a whistle when free-swimming animals were captured. It is possible that the emission of longer whistles may improve the perception of such whistles by other animals, potentially increasing the likelihood that such whistles are received by conspecifics. The communicative significance of whistle duration and loop number in distress calls remains unclear, but certainly warrants additional investigation.

This report on the underwater behavior and vocalizations of a distressed dolphin and its conspecifics highlights the value of opportunistic data collection and emphasizes the need for additional investigations of dolphin underwater behavior. The vast majority of the DD's behavior and all of her vocalizations occurred well below the surface of the water, as did almost all of the assistance provided to her by other dolphins. Better understanding of dolphin underwater behavior is essential for increasing our knowledge of dolphin behavior per se, not just their capacity for epimeletic behavior.

\section{References}

Altmann, J. (1974). Observational study of behavior: Sampling methods. Behaviour, 49, 227-265.

Amundin, M. (1991). Sound production in odontocetes with emphasis on the harbour porpoise, Phocoena phocoena (Unpublished doctoral dissertation.) University of Stockholm, Sweden. 
Brown, D. H., \& Norris, K. S. (1956). Observations of captive and wild cetaceans. Journal of Mammalogy, 311-326. doi:10.2307/1376730

Buckstaff, K. C. (2004). Effects of watercraft noise on the acoustic behavior of bottlenose dolphins, Tursiops truncatus, in Sarasota Bay, Florida. Marine Mammal Science, 20, 709-725.

Caldwell, M. C., \& Caldwell, D. K. (1965). Individualized whistle contours in bottlenosed dolphins (Tursiops truncatus). Nature, 207, 434-435.

Caldwell, M. C., \& Caldwell, D. K. (1966). Epimeletic (care-giving) behavior in Cetacea. In K. S. Norris (Ed.), Whales, porpoises and dolphins (pp. 755-789). Berkeley: University of California Press.

Caldwell, M. C., Caldwell, D. K., \& Tyack, P. L. (1990). Review of the signature-whistle hypothesis for the Atlantic bottlenose dolphin. In S. Leatherwood \& R. Reeves (Eds.), The bottlenose dolphin (pp. 199-234). San Diego, CA: Academic Press.

Clarke, C., Lea, J. S., \& Ormond, R. F. (2011). Reef-use and residency patterns of a baited population of silky sharks, Carcharhinus falciformis, in the Red Sea. Marine and Freshwater Research, 62, 668-675.

Clarke, C. R., Lea, J. S., \& Ormond, R. F. (2013). Changing relative abundance and behaviour of silky and grey reef sharks baited over 12 years on a Red Sea reef. Marine and Freshwater Research, 64, 909-919.

Clutton-Brock, T. (2009). Cooperation between non-kin in animal societies. Nature, 462(7269), 51-57.

Cockcroft, V. G., \& Sauer, W. (1990). Observed and inferred epimeletic (nurturant) behavior in bottlenose dolphins. Aquatic Mammals, 16, 31-32.

Connor, R. C., \& Norris, K. S. (1982). Are dolphins reciprocal altruists? American Naturalist, 119, 358-374.

Connor, R. C., Smolker, R. A., \& Richards, A. F. (1992). Dolphin alliances and coalitions. In A. H. Harcourt \& F. B. M. de Waal (Eds.), Coalitions and alliances in humans and other animals (pp. 415444). Oxford, England: Oxford University Press.

Cremer, M. J., Sliva Hardt, F. A., \& Tonello, A. J., Jr. (2006). Evidence of epimeletic behavior involving a Pontoporia blainvillei calf (Cetacea, pontoporiidae). Biotemas, 19, 83-86.

de Moura, J. F., da Silva Rodrigues, É., \& Siciliano, S. (2009). Epimeletic behaviour in rough-toothed dolphins (Steno bredanensis) on the east coast of Rio de Janeiro State, Brazil. Marine Biodiversity Records, 2(1). doi:10.1017/S1755267208000122

Dudzinski, K. M. (1996). Communication and behavior in the Atlantic spotted dolphin (Stenella frontalis): Relationships between vocal and behavioral activities (Unpublished doctoral dissertation). Texas A\&M University, Galveston, Texas.

Dudzinski, K. M., Sakai, M., Masaki, K., Kogi, K., Hishii, T., \& Kurimoto, M. (2003). Behavioural observations of bottlenose dolphins towards two dead conspecifics. Aquatic Mammals, 29, 108116.

Emlen, S. T. (1997). Predicting family dynamics in social vertebrates. Behavioural Ecology: An Evolutionary Approach, 4, 228-253.

Esch, H. C., Sayigh, L. S., Blum, J. E., \& Wells, R. S. (2009). Whistles as potential indicators of stress in bottlenose dolphins (Tursiops truncatus). Journal of Mammalogy, 90, 638-650.

Fertl, D., \& Schiro, A. (1994). Carrying of dead calves by free-ranging Texas bottlenose dolphins (Tursiops truncatus). Aquatic Mammals, 20(1), 53-56.

Fripp, D. (2005). Bubblestream whistles are not representative of a bottlenose dolphin's whistle repertoire. Marine Mammal Science, 21, 29-44.

Griffin, A. S., \& West, S. A. (2003). Kin discrimination and the benefit of helping in cooperatively breeding vertebrates. Science, 302(5645), 634-636.

Hamilton, W. D. (1964). The genetical evolution of social behaviour. Journal of Theoretical Biology, 7(1), 17-52.
Herzing, D. L. (1996). Vocalizations and associated underwater behavior of free-ranging Atlantic spotted dolphins, (Stenella frontalis) and bottlenose dolphins, (Tursiops truncatus). Aquatic Mammals, 22, $61-80$.

Janik, V. M. (2009). Acoustic Communication in Delphinids. Advances in the Study of Behavior, 40, 123-157

Janik, V. M., King, S. L., Sayigh, L. S., \& Wells, R. S. (2013). Identifying signature whistles from recordings of groups of unrestrained bottlenose dolphins (Tursiops truncatus). Marine Mammal Science, 29, 109-122.

King, S. L., Harley, H. E., \& Janik, V. M. (2014). The role of signature whistle matching in bottlenose dolphins, (Tursiops truncatus). Animal Behaviour, 96(C), 79-86. doi:10.1016/j.anbehav.2014.07. 019

King, S. L., Sayigh, L. S., Wells, R. S., Fellner, W., \& Janik, V. M. (2013). Vocal copying of individually distinctive signature whistles in bottlenose dolphins. Proceedings of the Royal Society B: Biological Sciences, 280, 1-9. doi:10.1098/rspb.2013.0053

Kuczaj, S. A., II, \& Eskelinen, H. C. (2014). Why do dolphins play? Animal Behavior and Cognition, 2, 113-127. doi:10.12966/abc.05. 03.2014

Kuczaj, S. A., II, \& Horback, K. M. (2013). Play and emotions. In S. A. Kuczaj \& S. Wantanabe (Eds.), Comparative perspectives on human and animal emotions (pp. 87-112). Tokyo, Japan: Springer.

Kuczaj, S. A., II, \& Makecha, R. (2008). The role of play in the evolution and ontogeny of contextually flexible communication. In D. K. Oller \& U. Griebel (Eds.), Evolution of communicative flexibility: Complexity, creativity, and adaptability in human and animal communication (pp. 254-277). Cambridge, MA: MIT Press.

Kuczaj, S. A., II, Winship, K. A., \& Eskelinen, H. C. (2015). Can bottlenose dolphins (Tursiops truncatus) cooperate when solving a novel task? Animal Cognition, 19, 543-550.

Lilly, J. (1963). Distress call of the bottlenose dolphin: Stimuli and evoked behavioral responses. Science, 139, 116-118.

Lilly, J. (1965). Vocal mimicry in Tursiops: Ability to match numbers and durations of human vocal bursts. Science, 147, 300-301.

Marler, P. (1955). Characteristics of some animal calls. Nature, 176, 6-8.

Marten, K., \& Marler, P. (1977). Sound transmission and its significance for animal vocalizations: I. Temperate habitats. Behavioral Ecology Sociobiology, 2, 271-290.

May-Collado, L. J. (2010). Changes in whistle structure of two dolphin species during interspecific associations. Ethology, 116, 1-10.

McBride, A. F., \& Hebb, D. O. (1948). Behavior of the captive bottlenose dolphin, Tursiops truncatus. Journal of Comparative Physiological Psychology, 41, 111-123.

Nowak, M. A. (2006). Five rules for the evolution of cooperation. Science, 314(5805), 1560-1563.

Park, K. J., Sohn, H., An, Y. R., Moon, D. Y., Choi, S. G., \& An, D. H. (2012). An unusual case of care-giving behavior in wild longbeaked common dolphins (Delphinus capensis) in the East Sea. Marine Mammal Science, 29, 508-514.

Pilleri, G. (1984). Epimeletic behaviour in Cetacea: Intelligent or instinctive. Investigations on Cetacea, 16, 30-48.

Richardson, L. W., Jacobson, H. A., Muncy, R. J., \& Perkins, C. J. (1983). Acoustics of white-tailed deer (Odocoileus virginianus). Journal of Mammalogy, 64, 245-252.

Ridgway, S. H. (1983). Dolphin hearing and sound production in health and illness. In R. R. Fay \& G. Gourevitch (Eds.), Hearing and other senses: Presentations in honor of E. G. Wever (pp. 247-296). Groton, CT: Amphora Press.

Ritter, F. (2007). Behavioral responses of rough-toothed dolphins to a dead newborn calf. Marine Mammal Science, 23, 429-433.

Russ, J. M., Jones, G., Mackie, I. J., \& Racey, P. A. (2004). Interspecific responses to distress calls in bats (Chiroptera vespertilionidae): A function for convergence in call design? Animal Behavior, 67, 10051014. 
Sayigh, L. S., Esch, C., Wells, R., \& Janik, V. (2007). Facts about signature whistles of bottlenose dolphins, Tursiops truncatus. Animal Behaviour, 74, 1631-1642. doi:10.1016/j.anbehav.2007.02.018

Scott, J. P. (1950). The social behavior of dogs and wolves: An illustration of sociobiological systematics. Annals of the New York Academy of Sciences, 51, 1009-1021.

Scott, J. P., \& Marston, M. V. (1950). Critical periods affecting the development of normal and mal-adjustive social behavior of puppies. The Pedagogical Seminary and Journal of Genetic Psychology, 77, 25-60.

Sharpe, T. L., \& Koperwas, J. (2003). Behavior and sequential analyses: Principles and practice. Thousand Oaks, CA: SAGE.

Siebenaler, J. B., \& Caldwell, D. K. (1956). Cooperation among adult dolphins. Journal of Mammalogy, 37, 126-128.

Silva, J. M., Jr., Silva, F. J., \& Sazima, I. (2005). Rest, nurture, sex, release, and play: Diurnal underwater behaviour of the spinner dolphin at Fernando de Noronha Archipelago, SW Atlantic. Journal of Ichthyology and Aquatic Biology, 9, 161-176.

Stefanski, R. A., \& Falls, J. B. (1972). A study of distress calls of song, swamp, and white-throated sparrows (Aves fringillidae) I. Intraspecific responses and functions. Canadian Journal of Zoology, 50, 1501-1512.

Stevens, J. R., Cushman, F. A., \& Hauser, M. D. (2005). Evolving the psychological mechanisms for cooperation. Annual Review of Ecology, Evolution, and Systematics, 36, 499-518. van der Woude, S. E. (2009). Bottlenose dolphins (Tursiops truncatus) moan as low in frequency as baleen whales. Journal of the Acoustical Society of America, 126, 1552-1562.

Vannoni, E., Torriani, M. V., \& McElligott, A. G. (2005). Acoustic signaling in Cervids: A methodological approach for measuring vocal communication in fallow deer. Cognition, Brain, and Behavior, 9, 551-566.

Warren-Smith, A. B., \& Dunn, W. L. (2006). Epimeletic behavior toward a seriously injured juvenile bottlenose dolphin (Tursiops sp.) in Port Phillip, Victoria, Australia. Aquatic Mammals, 32, $357-362$.

Watwood, S. L., Owens, E. C. G., Tyack, P. L., \& Wells, R. S. (2005). Signature whistle use by temporarily restrained and free- swimming bottlenose dolphins, Tursiops truncatus. Animal Behavior, 69, $1373-1386$.

Williams, E., \& Scott, J. P. (1953). The development of social behavior patterns in the mouse, in relation to natural periods. Behavior, 6, 3565.

Wood, F. G. (1954). Underwater sound production and concurrent behavior of captive porpoises, Tursiops truncatus and Stenella plagiodon. Bulletin of Marine Science of the Gulf and Caribbean, 3, 120-133.

Xitco, M. J., Gory, J. D., \& Kuczaj, S. A., II. (2001). Spontaneous pointing by bottlenose dolphins (Tursiops truncatus). Animal Cognition, 4, 115-123. 